Supporting Information

\title{
Synthesis of Diamond-Like Carbon as a Dielectric Platform for Graphene Field Effect Transistors
}

\author{
Birong Luo ${ }^{* \dagger}$, Aiheng Yuan ${ }^{\dagger}$, Shuai Yang ${ }^{\dagger}$, Luoqiao Han ${ }^{\dagger}$, Ran Guan ${ }^{\dagger}, J u n x i$ Duan ${ }^{\S}$, \\ Cheng Wang
}

†College of Physics and Materials Science, Tianjin Normal University, 300387 Tianjin, P. R.

China.

§School of Physics, Bejing Institute of Technology, 100081 Beijing, P. R. China.

¥Tianjin Key Laboratory of Wireless Mobile Communications and Power

Transmission, Department of Intelligence Science and Technology, Tianjin Normal University, 300387 Tianjin, P. R. China.

* Corresponding Author

E-mail: bluo@tjnu.edu.cn 
Table S1. Parameters of synthesized DLC films by FCVAD.

\begin{tabular}{c|c|c|c|c|c}
\hline $\begin{array}{c}\text { Experiment } \\
\text { number } \\
(\#)\end{array}$ & $\begin{array}{c}\text { Negative } \\
\text { bias } \\
\text { voltage }(\mathrm{V})\end{array}$ & $\begin{array}{c}\text { Arc } \\
\text { voltage } \\
(\mathrm{V})\end{array}$ & $\begin{array}{c}\text { Base } \\
\text { pressure } \\
(\mathrm{Pa})\end{array}$ & $\begin{array}{c}\text { Growth } \\
\text { temperature } \\
\left({ }^{\circ} \mathrm{C}\right)\end{array}$ & $\begin{array}{c}\text { Growth time } \\
(\mathrm{min})\end{array}$ \\
\cline { 1 - 2 } 1 & DC 60 & \multirow{2}{*}{50} & $\sim 10^{-4}$ & $\begin{array}{c}\text { Room } \\
\text { Temperature } \\
\text { (R.T.) }\end{array}$ & 5 \\
\hline 3 & DC 90 & & \\
\hline
\end{tabular}
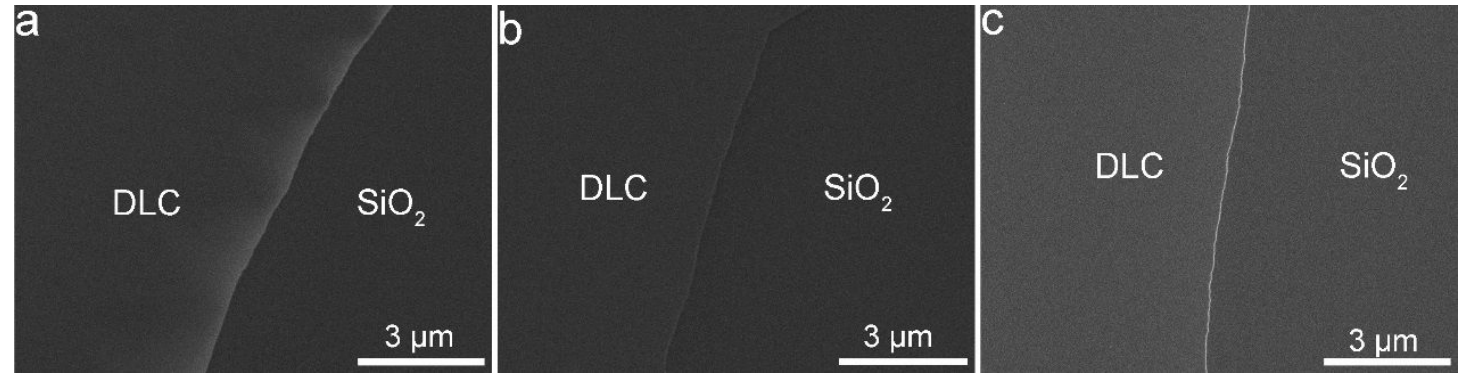

Figure S1. SEM images of as-deposited DLC films on $\mathrm{SiO}_{2} / \mathrm{Si}$ under fixed arc voltage $(50 \mathrm{~V})$ and varied bias voltage (a) -60 , (b) -90 and (c) $-110 \mathrm{~V}$ for $5 \mathrm{~min}$. 


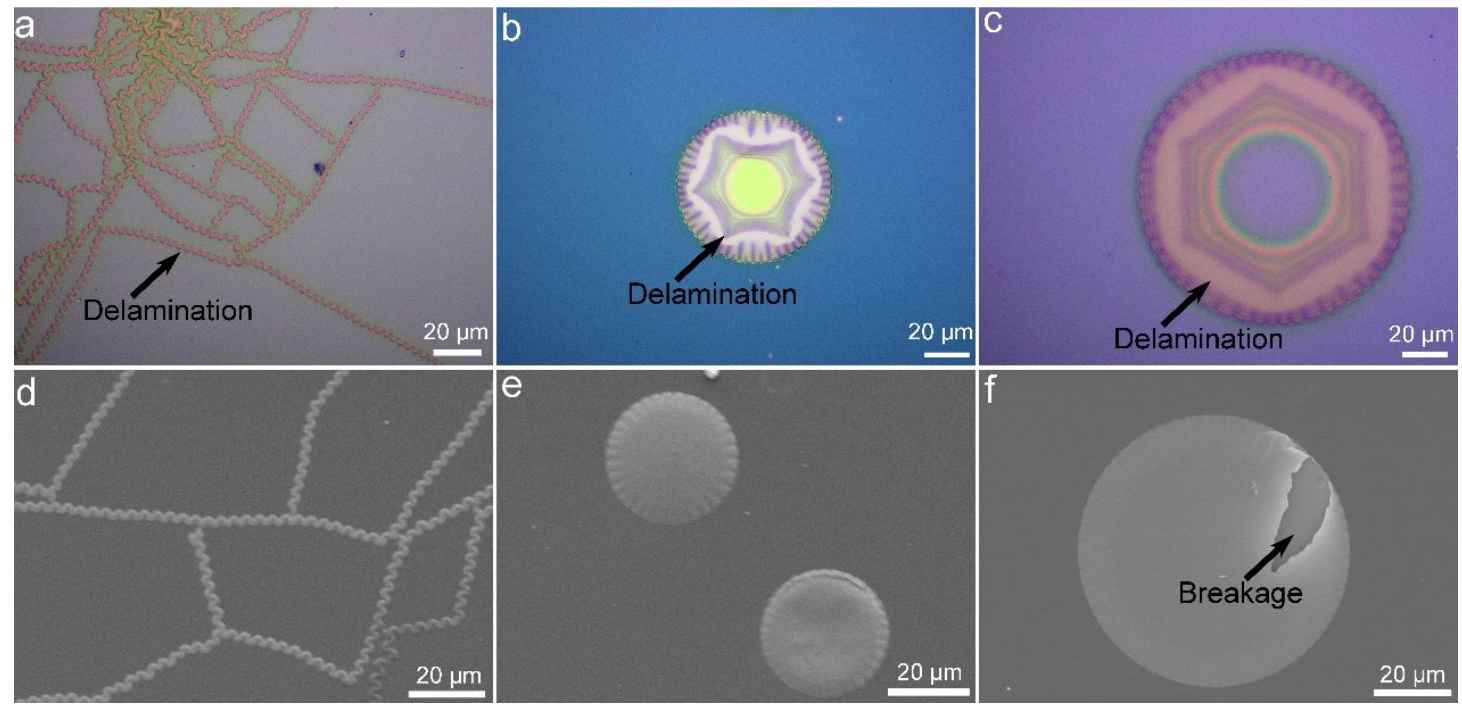

Figure S2. Optical and SEM images of as-deposited DLC films on $\mathrm{SiO}_{2} / \mathrm{Si}$ under fixed arc voltage $(50 \mathrm{~V})$ and varied bias voltage $(\mathrm{a}, \mathrm{d})-60,(\mathrm{~b}, \mathrm{e})-90$ and $(\mathrm{c}, \mathrm{f})-110 \mathrm{~V}$ for 5 min, showing DLC films delamination from $\mathrm{SiO}_{2} / \mathrm{Si}$ substrate without further annealing after exposure to air for a while.

Table S2. Summary of Raman and AFM characterization of DLC prepared by different bias voltage, and their comparison with $\mathrm{SiO}_{2}$.

\begin{tabular}{|c|c|c|c|c|c|c|c|}
\hline $\begin{array}{c}\text { Bias } \\
\text { voltag } \\
\mathrm{e}(\mathrm{V})\end{array}$ & $\begin{array}{c}\text { D-peask } \\
\text { position } \\
\left(\mathrm{cm}^{-1}\right)\end{array}$ & $\begin{array}{l}\text { G-peak } \\
\text { position } \\
\left(\mathrm{cm}^{-1}\right)\end{array}$ & $\begin{array}{c}\text { FWHM of } \\
\text { G-peak } \\
\left(\mathrm{cm}^{-1}\right)\end{array}$ & $\mathrm{I}_{\mathrm{D}} / \mathrm{I}_{\mathrm{G}}$ & $\begin{array}{l}\text { Thicknes } \\
\text { s (nm) }\end{array}$ & $\begin{array}{c}\text { Roughne } \\
\text { ss Ra } \\
\text { (nm) }\end{array}$ & $\begin{array}{l}\mathrm{Ra} \text { of } \\
\mathrm{SiO}_{2} \\
(\mathrm{~nm})\end{array}$ \\
\hline \multirow[t]{2}{*}{-60} & 1340 & 1560 & 205 & 0.48 & $5.01 \pm 0.3$ & $0.49 \pm 0.0$ & \\
\hline & & & & & 2 & 8 & \\
\hline \multirow[t]{2}{*}{-90} & 1331 & 1550 & 219 & 0.15 & $4.37 \pm 0.3$ & $0.35 \pm 0.0$ & $0.24 \pm 0.0$ \\
\hline & & & & & 0 & 6 & 6 \\
\hline \multirow[t]{2}{*}{-110} & 1295 & 1548 & 277 & 0.06 & $3.80 \pm 0.3$ & $0.34 \pm 0.0$ & \\
\hline & & & & & 5 & 7 & \\
\hline
\end{tabular}



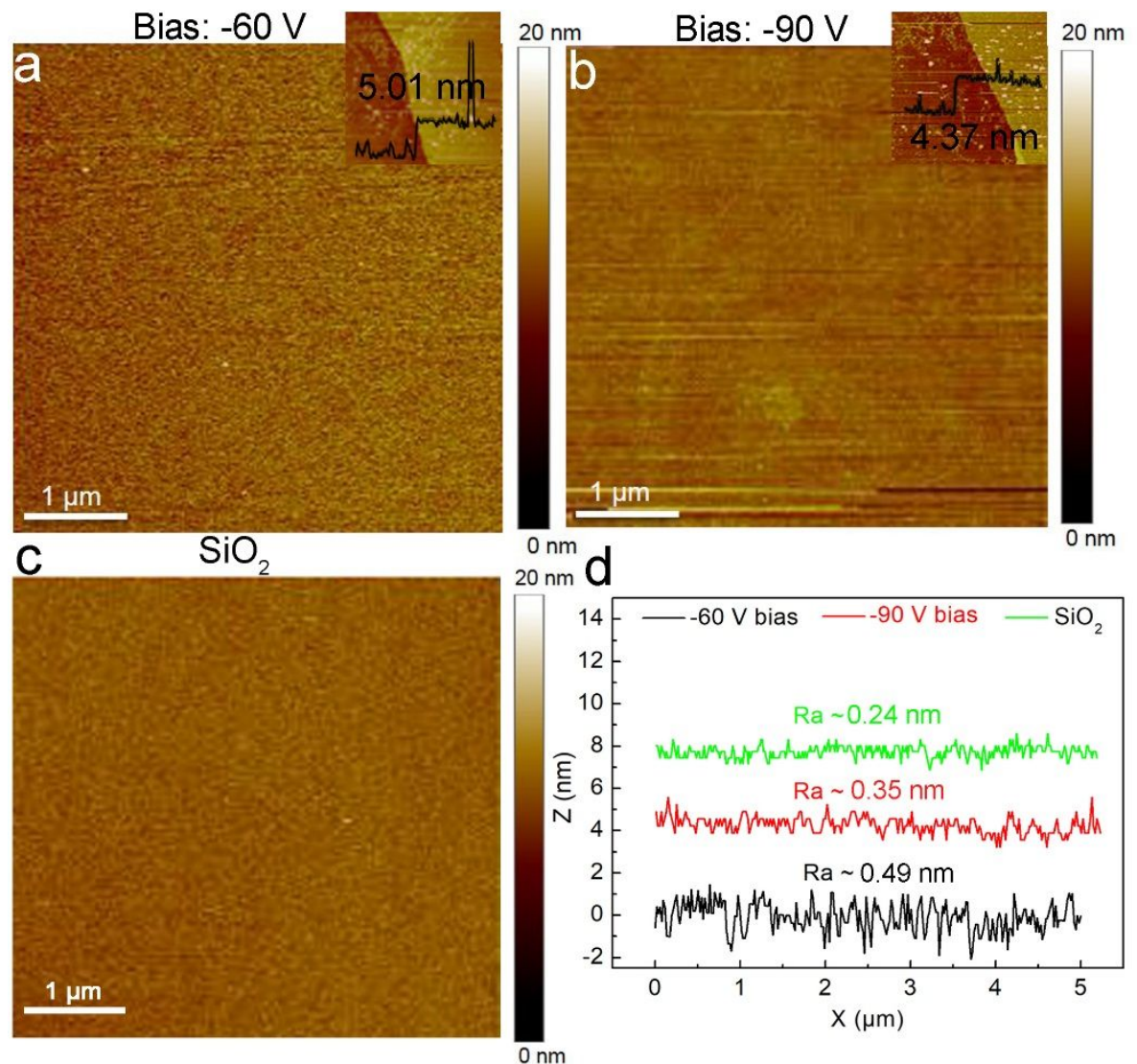

Figure S3. (a) AFM topography image of the surface of DLC films deposited under $60 \mathrm{~V}$, (b) $-90 \mathrm{~V}$ bias voltage, and (c) the surface of $\mathrm{SiO}_{2}$. Inset image in (a) and (b) is the corresponding AFM step height profile at the DLC edges. (d) The measured AFM average roughness (Ra) corresponding to (a), (b) and (c), respectively. 


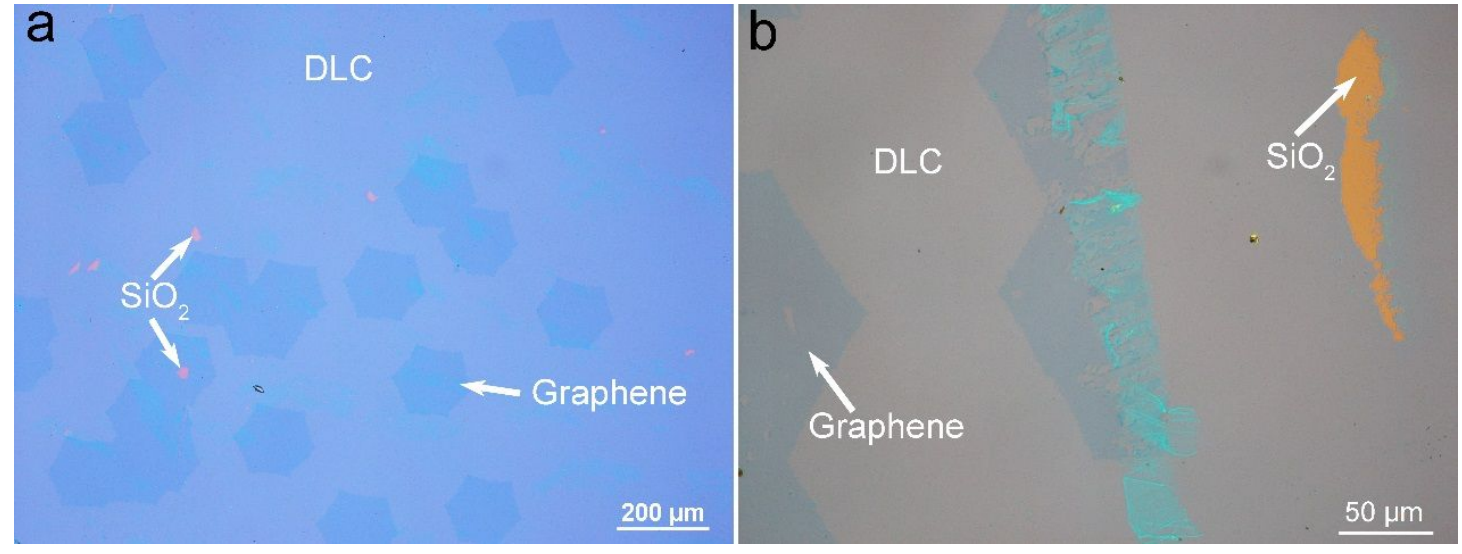

Figure S4. (a) Optical image of SG grains transferred on DLC template prepared under -110 and (b) $-60 \mathrm{~V}$ bias voltage, respectively, showing $\mathrm{SG}$ grains and exposed $\mathrm{SiO}_{2}$ surface under DLC breakage as denoted by the white arrows.

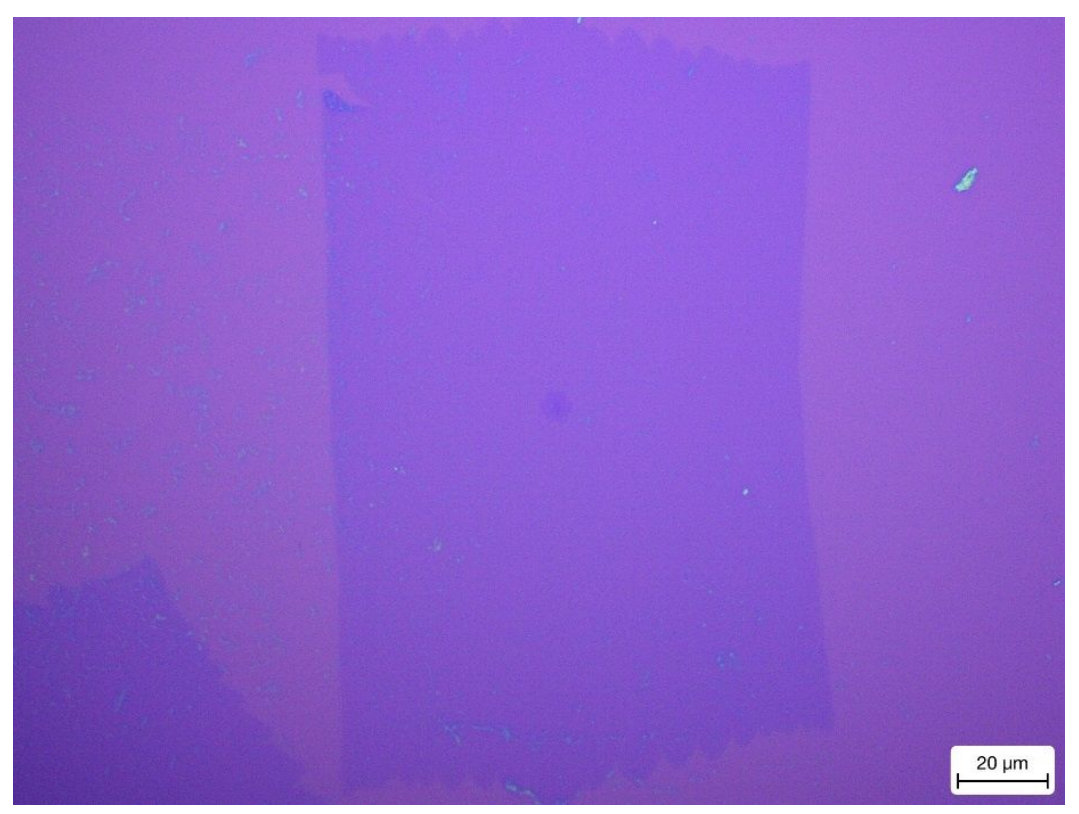

Figure S5. Optical image of $\mathrm{SG}$ grains transferred on $\mathrm{SiO}_{2} / \mathrm{Si}$ substrate. 


\section{FWHM(2D)}

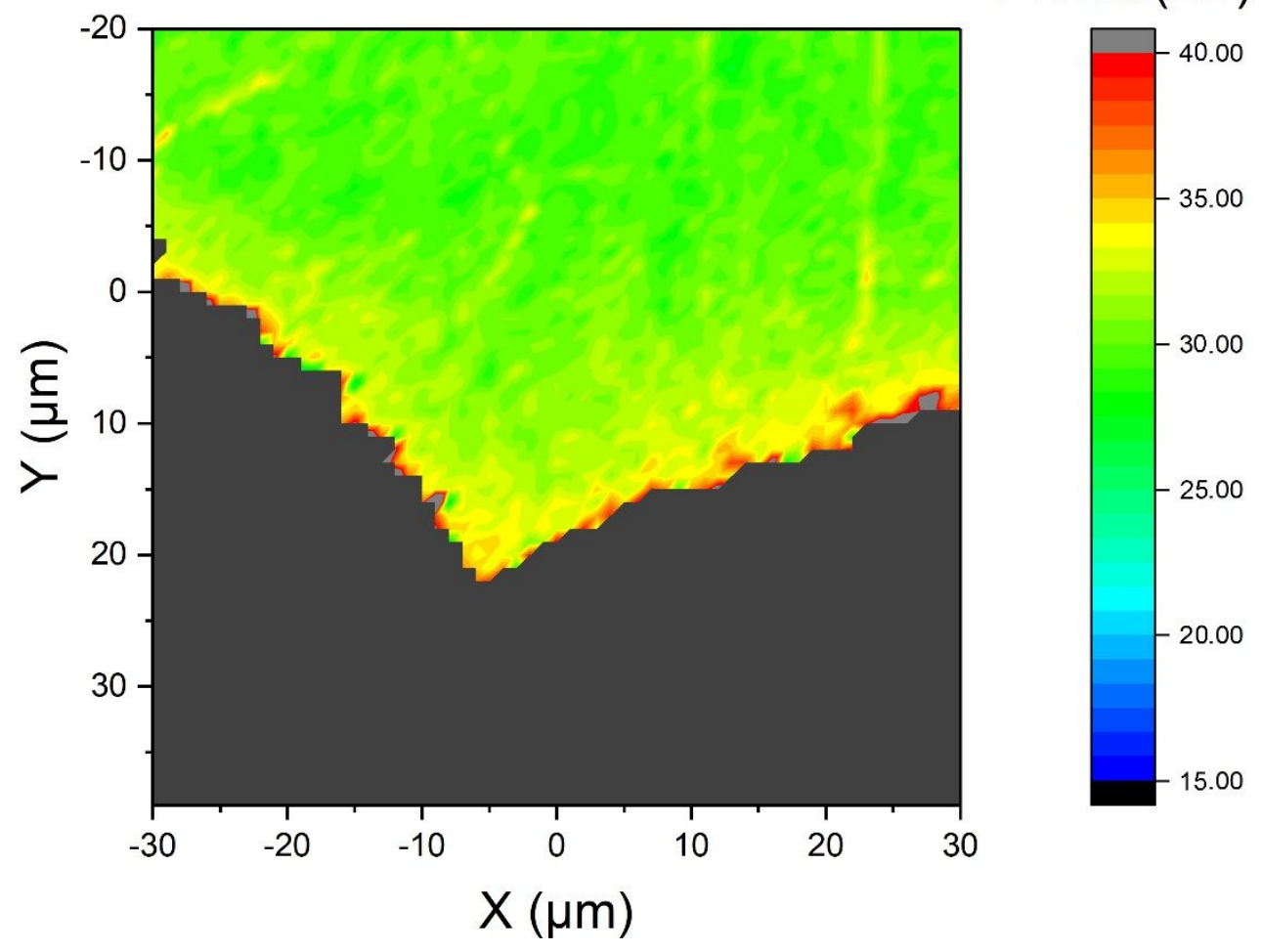

Figure S6. 2D-peak FWHM Raman mapping of a SG corner transferred onto -110 V DLC platform.
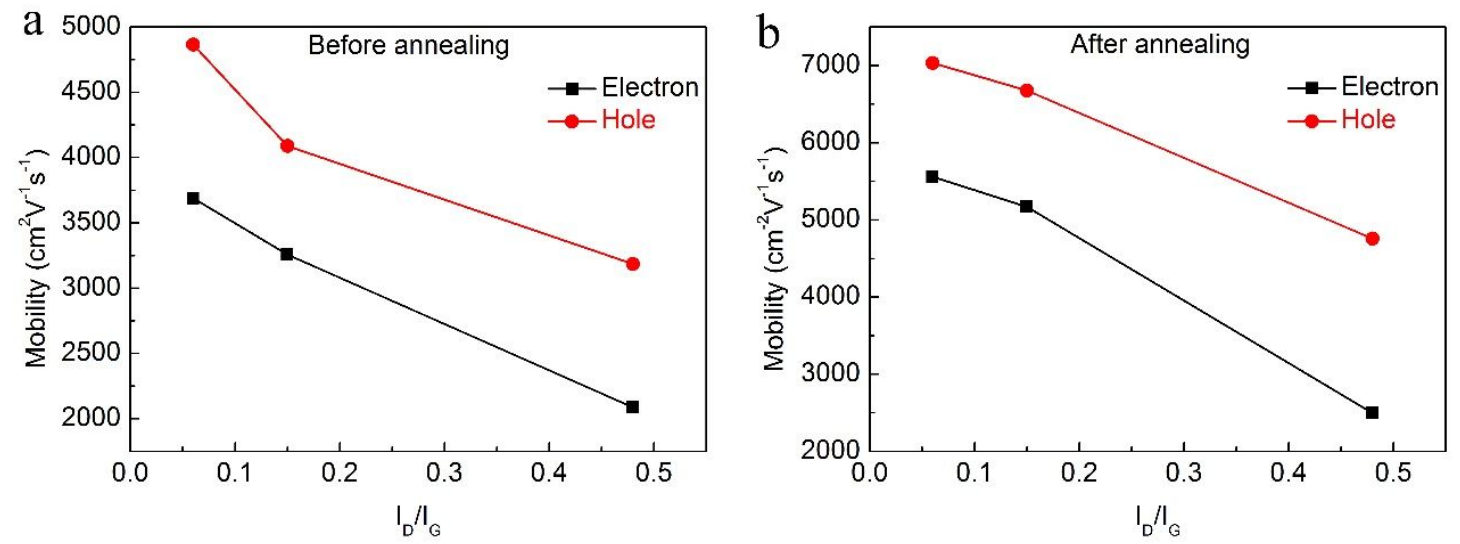

Figure S7. (a) Graphene hole and electron mobility before and (b) after annealing as a function of DLC template $\mathrm{I}_{\mathrm{D}} / \mathrm{I}_{\mathrm{G}}$. 


\section{Calculation of charge carrier density, $n_{0}$, in graphene at $0 V$ gate voltage}

The charge carrier density, $n$, can be calculated as:

$$
n=\frac{C_{o x}\left(V_{g}-V_{C P N}\right)}{e}
$$

where $C_{o x}$ is the gate capacitance of dielectrics $\left(11.5 \mathrm{nF} \mathrm{cm}{ }^{-2}\right.$ for $300 \mathrm{~nm}$-thick $\mathrm{SiO}_{2}$ platform, $11.3 \mathrm{nF} \mathrm{cm}{ }^{-2}$ for $\mathrm{DLC} / \mathrm{SiO}_{2}$ platform whose calculation are shown below ), $V_{g}$ is the gate voltage and $e$ is the electronic charge $\left(-1.6 \times 10^{-19} C\right)$. Therefore, at $V_{g}=0 \mathrm{~V}$, the charge density, $n_{0}$, for each platform is obtained as shown in Table $\mathrm{S} 1$.

Calculation of Field-effect mobility $\left(\mu_{F E}\right)$ of graphene on $\mathrm{SiO}_{2}$ and DLC platforms.

The Field-effect mobility, $\mu_{F E}$, can be obtained by:

$$
\mu_{F E}=L_{c h} g_{m} / W_{c h} C_{o x} V_{d s}
$$

where $L_{c h}$, and $W_{c h}$ are device channel length and width, respectively, $g_{m}$ is the transconductance of graphene which can be extracted by performing a linear fit close to the CNP point, $V_{D S}$ is the drain-source voltage $(0.01 \mathrm{~V}), C_{o x}$ is the gate capacitance of dielectrics. For $\mathrm{SiO}_{2}$ platform, $C_{o x}=11.5 \mathrm{nF} \mathrm{cm}{ }^{-2}$. For $\mathrm{DLC} / \mathrm{SiO}_{2}$ platform, $C_{o x}$ is calculated as:

$$
C_{\text {tot }}^{-1}=C_{\mathrm{SiO}_{2}}^{-1}+C_{D L C}^{-1}
$$

where $C_{\mathrm{SiO}_{2}}=11.5 \mathrm{nF} \mathrm{cm}{ }^{-2}, C_{D L C}=\varepsilon \varepsilon_{0} / d, \varepsilon$ is the relative dielectric constant of DLC $(\varepsilon \sim 3.2$, considering that relative dielectric constant values of DLC covers the range of $\left.2.7-3.8^{[1]}\right), \varepsilon_{0}=8.85 \times 10^{-12} \mathrm{~F} / \mathrm{m}$ is the dielectric constant of vacuum, $d$ is the DLC thickness $(\sim 4-5 \mathrm{~nm})$ as estimated from the AFM measurements. Based on this, $C_{t o t}$ is calculated as $\sim 1.13 \times 10^{-4} \mathrm{~F} \mathrm{~m}^{-2}$. 
Therefore, the Field-effect mobility, $\mu_{F E}$, for each platform is obtained as shown in Table 1.

[1] J. Laurikaitienè, Š. Meškinis, D. Adlienè, V. Šablinskas, S. Tamulevičius, V. Kopustinskas, M. Šniurevičiūtè, S. Mockevičienè, R. Gudaitis, Journal of Physics: Conference Series 2008, 100, 072036. 